\title{
Feministas y triperas. Mujeres y política en el área de género del club Gimnasia y Esgrima La Plata
}

\author{
Julia Hang*
}

* Licenciada en Sociología y doctora en Ciencias Sociales por la facultad de Humanidades y Ciencias de la Educación de la Universidad Nacional de La Plata. Actualmente es docente de Teoría Social Clásica en la Univerisdad Nacional de La Plata.. Correo electrónico: julita.hang@gmail.com

Fecha de recepción: 01/04/2020. Fecha de aceptación: 04/04/2020. 


\title{
Feministas y triperas. Mujeres y política en el área de género del club Gimnasia y Esgrima La Plata
}

\section{RESUMEN}

Este artículo se propone analizar el proceso de emergencia y consolidación del espacio de género del club Gimnasia y Esgrima La Plata, en el marco del avance del feminismo y movimiento de mujeres en el mundo, y particularmente en Argentina.

A partir del trabajo de campo etnográfico llevado a cabo junto con las mujeres que formaron el área de género del club en 2018, se mostrará el modo en que un conjunto de socias e hinchas se organiza políticamente con el objetivo de erradicar el machismo estructural del club e introducir la perspectiva de género entre sus dirigentes, deportistas y socios. Asimismo, se mostrará la forma en que tiene lugar un aprendizaje político particular que supone, por un lado, establecer negociaciones y concesiones con los dirigentes y entre las mismas integrantes del área, y por otro, establecer alianzas con otras instituciones, lo que supone tramitar de maneras novedosas las rivalidades futbolísticas en el marco de los ideales del feminismo y con el conflicto como elemento constitutivo.

El artículo permite iluminar algunas características de movimiento de mujeres argentino en relación con el proceso más amplio de conquista de derechos de las mujeres en la región, dentro del cual la disputa por el derecho a jugar, narrar, dirigir y gestionar el fútbol ha cobrado un gran protagonismo.

Palabras clave: política, mujeres, genero, club, fútbol

\section{Feminists and triperas. Women and politics in the gender department of Club Gimnasia y Esgrima La Plata}

\begin{abstract}
This article aims to analyze the emergency process and consolidation of the gender space of Gimnasia y Esgrima de La Plata club, in the context of the advancement of feminism and women's movement in Argentina.

Based on the ethnographic field work with the women who formed the gender area in 2018, it seeks to know how a group of female members and supporters of Gimnasia organize politically in the club with the aim of eradicating structural machismo and introduce gender perspective among its leaders, athletes and members. Consider the way in which a particular political learning takes place, which implies on the one hand establishing agreements and concessions with the executive committee and among the members of the area. And on the other hand, establish alliances with other institutions, which means processing football rivalries in new ways within the framework of the ideals of feminism, with conflict as a constituent element.

The article allows to illuminate some characteristics of the broader social movement that refers to the Argentine women's movement in relation to the broader process of conquering women's rights in the region, within which the dispute for the right to play, narrate, direct and manage football has gained great prominence.
\end{abstract}

Keywords: politics, women, gender, club, football. 


\section{INTRODUCCIÓN}

El 8 de septiembre de 2019 fue un día histórico para la hinchada de Gimnasia y Esgrima de La Plata. Diego Armando Maradona, el máximo ídolo del fútbol argentino, debutó como director técnico del equipo de fútbol masculino del Lobo ${ }^{1}$, un club de la primera división del fútbol argentino. Gimnasia nunca ganó un campeonato de la liga en la época del profesionalismo, y su hinchada se caracteriza por el amor incondicional ofrecido a un equipo que le devuelve pocas alegrías ${ }^{2}$. La llegada de Maradona a Gimnasia fue para sus hinchas un sueño, un paréntesis en su historia de tanto sufrimiento. La ciudad de La Plata, una ciudad universitaria de casi un millón de habitantes que dividen su pasión futbolística entre los clubes de Gimnasia y Estudiantes de La Plata, se vio revolucionada con la presencia de Maradona. Periodistas de todo el mundo se acercaron a la capital de la provincia de Buenos Aires a cubrir el debut de Diego ${ }^{3}$ y fanáticos de todo el país viajaron para ver la vuelta de su ídolo al fútbol argentino. Gimnasia afilió en muy pocos días a 5000 nuevos socios y multiplicó la venta de camisetas e indumentaria oficial, obteniendo cuantiosos ingresos para un club cuya economía se encuentra en un profundo déficit. El "fenómeno Maradona», que ha sido objeto de la literatura sociológica y al que se han dedicado incluso jornadas de debate en universidades nacionales, llegó a este pequeño club platense, transformando su vida y la de sus hinchas para siempre.

Maradona es para la sociedad argentina uno de los grandes héroes nacionales. Contradictorio y polémico, según Pablo Alabarces, uno de los investigadores que más ha indagado en la importancia del jugador en la cultura de masas nacional, Maradona fue la figura excluyente del relato patriótico durante al menos dos décadas (2013, p. 34). Esto se debe, para el autor, a que combina una serie de rasgos sobre los que se articula la narrativa heroica: su condición de género (es varón) y de clase (de origen popular). Es, además, un jugador excepcional, que hizo dos goles únicos a Inglaterra en 1986 cuatro años después de la guerra de Malvinas en la que se enfrentaron ambos países. Ese partido fue leído por gran parte de la sociedad argentina como la continuidad de tal enfrentamiento bélico, en el que de la mano

\footnotetext{
1 En este trabajo las palabras nativas irán en cursiva y los fragmentos de entrevista entrecomillados. Lobo es una de las maneras de nombrar a Gimnasia, pues su estadio se encuentra en el bosque de la ciudad de La Plata.

2 En efecto, en su larga historia de vida, Gimnasia obtuvo solo dos títulos: en 1929 (cuando el fútbol aun era amateur) y en 1994, la Copa Centenario.

3 En este artículo nos referiremos a Diego Maradona como Maradona, Diego o El Diez (por el número que el jugador utilizaba en su camiseta). De todos estos modos es popularmente conocido por la hinchada argentina.
} 
de Maradona se logró derrotar a quienes nos habían vencido en la guerra ${ }^{4}$. Maradona es una figura central en la cultura popular argentina (Archetti, 2008, p. 271). Retirado de su carrera como jugador, ha sido entrenador de múltiples equipos, tanto en Argentina como en otros países del mundo, sin pasar nunca desapercibido. Porque - como sostiene Alabarces—, además del héroe, es un personaje con fuertes posicionamientos políticos, y que aun cuando ya no pudo seguir jugando, su discurso y lengua filosa siempre lo devolvían al centro de la escena.

A pesar de la euforia que generó en la mayoría de sus hinchas, la llegada de Maradona a Gimnasia en 2019 no alegró a toda su hinchada por igual. Al gran ídolo popular argentino se lo acusa de ejercer violencia de género hacia sus parejas y de ser un padre irresponsable que no ha reconocido a algunos de sus hijos. Para muchas mujeres argentinas, Maradona representa la idea de hombre machista y misógino que desde algunos sectores del feminismo se apunta a transformar.

La vuelta de Maradona al fútbol argentino se dio en un contexto de gran avance del movimiento de mujeres y feminista que se ha estado manifestando con fuerte presencia en las calles, con particular énfasis desde 2015, cuando tuvo lugar el primer \#NiUnaMenos ${ }^{5}$, una movilización masiva de escala nacional en contra de la violencia machista, y que con los debates por la legalización del aborto en el congreso nacional durante 2018 cobró una masividad nunca antes vista. El 5 de marzo de 2018, la Campaña Nacional por el Aborto Legal, Seguro y Gratuito presentó por séptima vez en la Cámara de Diputados el proyecto de Ley de Interrupción Voluntaria del Embarazo. Este obtuvo media sanción en la Cámara de Diputados el 14 de junio de ese mismo año, pero fue rechazado el 9 de agosto en el Senado de la Nación. Ambas jornadas de debate y votación fueron acompañadas por multitudinarias movilizaciones y se constituyeron en hitos del movimiento de mujeres en Argentina.

Uno de los impactos del avance de este movimiento a partir del \#NiUnaMenos tiene que ver con la reconversión de demandas históricas del feminismo en problemas públicos que adquirieron legitimidad, masividad y transversalidad en otros sectores sociales (Natalucci y Rey, 2018, p. 28). Su novedad es la llegada a lugares hasta antes impensados. El mundo del fútbol, que en Argentina se estructuró desde

\footnotetext{
4 El periodista Andrés Burgo rastrea en su libro El partido los días previos al enfrentamiento entre Argentina e Inglaterra y el lenguaje bélico con el que los medios del mundo anticipaban el partido, así como las continuidades que establecían con la guerra. Los jugadores y el cuerpo técnico relatan que, a pesar de su intento por desvincular ambos acontecimientos, no podían evitar sentirse fuertemente interpelados por tales discursos y sufrir una presión particular por ganar este partido.

5 El \#NiUnaMenos refiere a la enorme movilización de mujeres que se cristaliza el 3 de julio de 2015 en todo el país a partir del aumento de los feminicidios. El fenómeno tuvo una gran visibilización a partir del uso de las redes sociales y medios de comunicación, que contribuyeron a la instalación de la demanda en la agenda pública y la consiguiente ocupación de las calles por las mujeres en todas las ciudades del país.
} 
sus orígenes como un espacio «de hombres y para hombres» (Álvarez Litke, 2018; Hijós, 2018), comenzó a ser tensionado, de forma masiva, desde diversos sectores del feminismo, que durante muchos años lo habían ignorado como objeto de disputa, a pesar de que las mujeres siempre estuvieron vinculadas con el fútbol, como hinchas y espectadoras (Conde y Rodríguez, 2002) y como jugadoras (Elsey, 2019; Pujol, 2019). Elsey (2019) señala que, para el caso del fútbol, su construcción como objeto de disputa se para sobre el trabajo de activistas de base, como las profesoras de educación física Lorena Berdula y Mónica Santino, quienes desde hace más de veinte años trabajan por conquistar el derecho al fútbol, lo que implica para ellas un cuestionamiento al orden patriarcal que estructura la sociedad.

En este contexto, Gimnasia creó su área de género en el año 2018, un espacio institucional ocupado por mujeres que se reconocen como feministas ${ }^{6}$ que tiene por objetivo principal erradicar el machismo estructural que caracteriza al club. Este espacio, formado por hinchas mujeres, socias del club y deportistas, se propone conquistar y transformar desde una perspectiva de género los espacios en los cuales se gestiona la vida social y deportiva del club. La llegada de Maradona al club, luego de un año y medio de intensa actividad del área de género que posicionaba al club como pionero en visibilizar y trabajar por la eliminación de las desigualdades y violencias de género, significó un punto de quiebre para sus integrantes, una situación problemática (Cefaï, 2011) que evidenció no solo la heterogeneidad de posicionamientos y concepciones en torno a la manera de comprender los problemas de género que las había agrupado en el espacio, sino también los límites de su posibilidad de incidir en la política del club. La noción de situación problemática permite ir recorriendo junto a las actoras las estrategias que van movilizando y las formas como van entrando en relaciones complejas de cooperación y conflicto (Cefaï, 2011, p. 138) a partir de acontecimientos que requieren resoluciones en función de los contextos en que van teniendo lugar. En ese camino se engendran nuevas asociaciones. Las mujeres que hoy conforman el área de género de Gimnasia no son las mismas que cuando inició la investigación, y este trabajo da cuenta de algunos eventos que, desde el punto de vista de las protagonistas, significaron puntos de quiebre en el modo en que se organizan políticamente en el club, en los objetivos que las convocan y en las alianzas que van estableciendo. Por lo tanto, las descripciones de eventos presentadas en este escrito no responden a una linealidad temporal, sino que son tomadas en tanto acontecimientos significativos desde el punto de vista de las actoras y, por lo tanto, permiten dar cuenta de la multiplicidad

\footnotetext{
6 Las categorías "feministas», "machistas» o "género», cuando aparecen en cursiva, refieren a categorías de la práctica cuyos sentidos este texto apunta a dilucidar.
} 
de sentidos movilizados en torno a situaciones que las convocaron a debatir, actuar $\mathrm{y}$ articular entre ellas y con otros actores.

Durante los días previos al debut oficial del DT, las pibas ${ }^{7}$ discutieron cómo posicionarse frente a la llegada del Diez: si emitir un comunicado público repudiando a Maradona, si realizar acciones individuales, si dialogar con los dirigentes o si aceptar su llegada sin más ya reconociendo que, como mencionó Jeny, una de las integrantes del área, el pueblo tripero ${ }^{8}$ estaba feliz. Finalmente, optaron por no emitir un comunicado público, entendiendo que la única posibilidad de ser reconocidas como interlocutoras legítimas de los dirigentes del club, de los socios y de los hinchas era no mostrarse contrarias al hecho que más alegría había traído a la hinchada tripera en los últimos años. Tal como comentó Jeny: «A pesar de la tristeza que me genera que nuestro club contrate e idolatre a un hombre violento, entiendo que le da alegría a la gente, y yo con la felicidad del pueblo no me meto». Rastrear el delicado proceso a través del cual las pibas lograron construir tal consenso contribuye a iluminar una pregunta más general sobre el proceso de constitución del movimiento de mujeres argentino, donde las experiencias de sus integrantes son de una gran diversidad.

Este artículo se sitúa, por lo tanto, en la intersección entre el campo de los estudios sociales del deporte —en particular aquellos que han trabajado la relación entre clubes y política- y los estudios sobre el movimiento de mujeres y feminismos contemporáneo. Tiene como principal objetivo describir y analizar los modos en que un colectivo de mujeres feministas se organiza políticamente en el club Gimnasia y Esgrima La Plata (CGE) y disputa poder, combinando dos lógicas

\footnotetext{
«Las pibas» es una categoría nativa utilizada por algunas de las integrantes del área para referirse a sí mismas, y se suele utilizar también para alentar a las jugadoras de fútbol. En Argentina, el término "pibe» se aplica históricamente a los varones jóvenes, e incluso Archetti (2008) ha demostrado la centralidad que tal concepto ha ocupado en el estilo y el imaginario futbolístico que define lo argentino (siempre masculino). Para el antropólogo, el jugador argentino por excelencia es «el pibe», figura de la cual Maradona es su máximo exponente. De cuerpo pequeño, jugador habilidoso, capaz de improvisar, dueño de una viveza y creatividad únicas, el pibe es libre, contradictorio, autodestructivo. De poca moral y responsabilidad social, se le perdona todo, porque la alegría que provee con su destreza corporal es mayor. Los pibes son espejos y, asimismo, operan como modelos que definen un estilo, una manera de jugar (Archetti, 2008, p. 274). Si bien no es el objetivo de este trabajo profundizar en la significación de tal categoría, vale la pena preguntarse si se trata de una reapropiación que las mujeres realizan de la categoría pibe, entendiendo el dinamismo de la disputa por las significaciones populares y la tensión continua en la definición de la cultura popular en las relaciones de tensión continua (relación, influencia y antagonismo) con la cultura dominante (Hall, 1984, p. 6).

8 Según relata Godio (2009), en 1914 el club Estudiantes de La Plata expulsó a los jugadores que no residían en el casco urbano, quienes fueron incorporados por Gimnasia. Eran habitantes de la zona periférica de Berisso y trabajadores de sus frigoríficos, y se los denominó «triperos» de manera despectiva, término que se utiliza hasta el día de hoy por los simpatizantes de Gimnasia, pero ahora con un valor positivo.
} 
políticas: la del mundo del fútbol y la del feminismo. Esta combinación supone una negociación y una articulación constante, tanto entre las mujeres que forman el espacio, como con los dirigentes y socios del club.

Para el análisis se privilegió una metodología de corte etnográfico, donde se combinaron entrevistas en profundidad con las mujeres que forman parte del área de género del club Gimnasia y Esgrima La Plata y observación participante en diversas instancias significativas para ellas: reuniones del área, partidos de fútbol femenino, marchas y movilizaciones por los derechos de las mujeres y disidencias y eventos organizados tanto por ellas como por el club. El trabajo de campo tuvo lugar entre junio de 2018 y febrero de 2020.

\section{La participación política de las MUJERES EN LOS CLUbeS DE fÚtbol ARGENTINOS}

El club Gimnasia y Esgrima La Plata, como todos los clubes argentinos, es una asociación civil sin fines de lucro. Al contar con fútbol masculino profesional, en él conviven la hiperprofesionalización del fútbol con la lógica de la asociación civil (Moreira, 2018), que es la lógica imperante desde la fundación de los clubes a principios del siglo XX. El formato de asociación civil sin fines de lucro implica, en primer lugar, generar un bien común para sus afiliados, y en segundo lugar, un beneficio que se extiende a la comunidad en general que tiene que ver con su función social. En este sentido, en Gimnasia no solo se practica fútbol masculino profesional, sino que se ofrecen una multiplicidad de deportes amateurs, además de que cuenta con jardín de infantes, escuela primaria y secundaria. En paralelo con las actividades deportivas — mencionan De Marziani y Pierini (2019) — se realizan distintas jornadas y eventos de la mano de la Subcomisión de Cultura y Museo, Gimnasia Social, Juventud Gimnasista, Filiales y otras áreas que realizan su aporte sociocultural voluntariamente.

A diferencia de lo que sucede en las ligas europeas y en otros países latinoamericanos donde los clubes son sociedades anónimas, los dirigentes de los clubes argentinos llegan a la Comisión Directiva por medio de los mecanismos electorales estipulados en sus estatutos. Cada un período de dos, tres o cuatro ańos (dependiendo del estatuto del club), los socios eligen a sus representantes. En el caso de CGE, la Comisión Directiva que gestionaba el club al momento de llevar adelante el trabajo de campo fue electa en 2016 con el apoyo del 53\% de los socios y desde entonces ha estado gestionando el club en un contexto económico desfavo- 
rable ${ }^{9}$. Desde marzo de 2017, el club se encuentra en un proceso de convocatoria de acreedores debido a la deuda millonaria que el club venía acumulando. En su comisión directiva, solo dos mujeres ocupan cargos menores, dato que destacan Luisina y Belén ${ }^{10}$, las dos hinchas que crearon el área de género en el club. Además, señalan que en el club los roles están "re generizados», que las mujeres son secretarias, y que son los varones quienes ocupan posiciones de poder. Este bajo porcentaje de mujeres participantes en la conducción de los clubes no es característica del CGE, sino que es un denominador común en todos los casos de los clubes que cuentan con fútbol profesional, algunos de los cuales no cuentan con ninguna mujer en sus espacios de poder, a pesar de que el artículo 20bis de la Ley del Deporte reformada en 2016 pareció atender la problemática del cupo femenino en las listas que se presentan a elección de Comisión Directiva ${ }^{11}$. En total, de los clubes de fútbol que disputan el torneo de primera división, el 6,07\% son mujeres. De ellas, solo una es presidenta (Lucía Barbuto en el club Atlético Banfield), una es vicepresidenta tercera y el resto son secretarias de actas, vocales suplentes, revisoras de cuentas, miembros del tribunal de conducta o de la comisión fiscalizadora.

Existe una gran cantidad de bibliografía que ha abordado la relación entre política y deporte en los clubes argentinos. Tanto desde la historiografía, como desde la sociología y la antropología se ha dado cuenta del modo en que la política es constitutiva de tales instituciones. Por un lado, por los lazos que dirigentes establecen con el campo político local, nacional o provincial, lo que muchas veces implica beneficios para los clubes y también para los dirigentes que pueden capitalizar los beneficios sociales y políticos obtenidos en los clubes (Moreira, 2010; Rein, 2015). Y por otro, por el modo en que el formato jurídico de los clubes argentinos habilita un tipo de aprendizaje político y democrático específico (Frydenberg, 2002; Frydenberg y Daskal, 2010; Daskal y Moreira, 2017). Los clubes argentinos afirman estos estudios - son escuelas de democracia y civismo: son instancias de desarrollo de virtudes cívicas, de entrenamiento en la vida social y democrática, y

\footnotetext{
9 El 14 de diciembre de 2019 hubo elecciones en Gimnasia, tras un proceso conflictivo de alianzas y desacuerdos entre las diferentes listas. Finalmente, Pellegrino resultó reelecto con el $61 \%$ de los votos. Días antes de la elección, Maradona había afirmado públicamente que solo seguiría en el club de la mano de Pellegrino, lo que terminó de definir el voto en favor de este último.

10 En este texto los nombres de mis interlocutoras han sido modificados para resguardar su intimidad.

11 El artículo 20 bis de la Ley n. ${ }^{\circ} 20655$ establece un mínimo para mujeres y jóvenes, incluyéndolos en la misma categoría, como se puede ver en el citado artículo: «Las listas que se presenten para la elección de integrantes de la Comisión Directiva en las asociaciones civiles deportivas de primer grado del Sistema Institucional del Deporte y la Actividad Física, deben tener entre los candidatos a los cargos titulares a elegir, un mínimo de $20 \%$, en conjunto, de mujeres y de personas jóvenes entre 18 y 29 años de edad, que reúnan las condiciones propias del cargo para el cual se postulen y no estén comprendidos en alguna de las inhabilidades estatutarias
} 
de despliegue de reglas que deben ser respetadas por los participantes a la manera de un sistema político.

Sin embargo, estos trabajos no dieron cuenta de que la participación de las mujeres en este sistema democrático ha sido históricamente desalentada por muchos medios. No solo porque algunas instituciones excluían de la condición de socias plenas a las mujeres, negándoles la posibilidad tanto de votar como de ser electas como autoridades ${ }^{12}$, sino también porque el amateurismo de los dirigentes de los clubes argentinos que realizan su trabajo sin cobrar remuneración conlleva, como muestra Moreira (2018), a una concentración de cargos administrativos en provecho de aquellos que disponen del tiempo necesario para cumplir las funciones de manera gratuita. Puede pensarse que las mujeres, cuyo acceso al ocio y tiempo libre ha sido limitado, se han visto imposibilitadas de acceder a tales cargos ${ }^{13}$.

Ahora bien, a pesar de esta baja participación de las mujeres en los lugares de decisión de los clubes de fútbol argentinos, el acercamiento del feminismo al mundo del deporte no es una novedad histórica. Algunas investigaciones han rastreado sus vínculos, dando cuenta de una temprana relación entre ambos. Tanto Scharagrodsky (2014) como Anderson (2017) coinciden en señalar la importancia del Primer Congreso de Feminismo Internacional que tuvo lugar en Argentina en 1910, en el cual el acceso a la cultura física y el deporte aparecía ya como un objeto de disputa para las feministas de la época. Sin embargo, mientras Scharagrodsky sostiene que las feministas destacaban la importancia del acceso a la actividad física, pero que lo hacían desde un paradigma que tendía a reforzar el mandato materno, Anderson muestra que la organización política de estas mujeres — que tienen como primer antecedente la participación en dicho congreso- en torno al deporte y la actividad física, las llevó a encontrar instrumentos a través de los cuales construir y definir una agencia política desacoplada de la maternidad (2017, p. 6). Anderson sostiene que, en una época en la cual aún las mujeres no gozaban del derecho a voto, los clubes les permitían tener proyectos políticos, aun cuando el objetivo era poder juntarse a jugar y muchos de ellos no hayan perdurado en el tiempo.

12 Tal es el caso, por ejemplo, del club Universitario de Buenos Aires: recién el 5 de noviembre de 2018 los socios votaron en asamblea la reforma del estatuto otorgando a las mujeres la condición de socias plenas. Para ampliar, ver https://www.ambito.com/historico-giro-el-club-cuba-las-mujerespodran-ser-socias-plenas-n4038559)

13 Como muestra una investigación llevada a cabo por Caminotti (2017), que señala las desigualdades de género en el trabajo doméstico no remunerado, al cual las mujeres dedican el $75 \%$ de su tiempo, contra un $24 \%$ de dedicación en el caso de los hombres (INDEC, 2013). De esta manera, "cuando las mujeres se insertan en el mercado laboral, generalmente continúan a cargo de las actividades de cuidado y organización de sus hogares, en detrimento de su tiempo de descanso y ocio» (PNUD, 2014, p. 25). 
Tomando en cuenta tales antecedentes, en este artículo se buscará poner de manifiesto los modos diversos según los cuales las mujeres, a pesar de no ocupar cargos en las comisiones directivas, se las ingenian para ejercer poder en los clubes, tanto a partir de la creación del área de género en un contexto histórico que encuentra una recepción favorable a sus demandas como a partir de las instancias de sociabilidad desplegadas desde y en el club.

Impulsados por el avance del movimiento de mujeres en Argentina, una multiplicidad de organismos públicos y organizaciones de la sociedad civil han ido creando espacios dedicados a trabajar las cuestiones vinculadas con el género, tales como los cupos, las violencias y el machismo estructural de la sociedad. Los clubes de fútbol no han sido ajenos a este proceso. Desde el año 2017 fueron creando espacios específicos para abordar las cuestiones de género: áreas de género; creación e implementación de protocolos de acción contra la violencia de género; secretarías o departamentos de mujeres. A su vez, hinchas y socias mujeres crearon agrupaciones feministas por fuera de las instituciones, pero cuyas demandas apuntan a tener un impacto en la vida institucional de los clubes. Los formatos y vinculaciones de estos espacios en cada club. Así, no solo proliferaron los espacios de género en los clubes de fútbol, sino que también la demanda por la visibilización del fútbol femenino y su profesionalización encontraron respuesta en la Asociación de Fútbol Argentino, cuyo presidente, Chiqui Tapia, anunció en marzo de 2019 su profesionalización, haciéndose eco de los reclamos que el movimiento de mujeres, encabezado por la jugadora Maca Sánchez, había estado llevando adelante ${ }^{14}$.

La creación del área de género del CGE tuvo lugar en el marco de un proceso que venía teniendo lugar en otros clubes de la primera división, que en algunos casos se enmarcan en el entramado institucional, como subsecretarías de género, y en otros como comisiones o subcomisiones. El surgimiento de estos espacios ha sido posibilitado por el formato que los clubes tienen en nuestro país y la politización intrínseca y estructural del fútbol argentino.

\section{TRIPERAS Y FEMINISTAS: EL ÁREA DE GÉNERO DE GIMNASIA}

El área de género del CGE fue lanzada oficialmente en junio de 2018. Se trata de un espacio institucional dependiente de la Secretaría de Cultura y Museo del club,

\footnotetext{
14 Para profundizar sobre el proceso de profesionalización del fútbol femenino, recomiendo las notas de la periodista Ayelén Pujol publicadas en Página 12, "La nueva era ya se vislumbra», del día 17/04/2019 en https://www.pagina12.com.ar/187051-la-nueva-era-ya-se-vislumbra y «El fútbol también es de las pibas», publicada el 16/03/2019 en https://www.pagina12.com.ar/181431-elfutbol-tambien-es-de-las-pibas?fbclid=IwAR23My0rHxr67ANbVteY2fCQ7Ib_0iAkZp7JBI0ddRM MntT7Do9AUGzRuUg
} 
formado por mujeres que se identifican como feministas, que tiene como objetivo principal trabajar por la introducción de la perspectiva de género y la erradicación del «machismo» en el club.

Una nota publicada en un medio digital platense llamó mi atención y decidí acercarme a quienes conformaban el área para conversar. Escribí un mail a la casilla de correo que mencionaban para contactarlas y rápidamente me respondieron invitándome a participar de una reunión en la sede social del club, a la que asistí sin saber bien con qué me iba a encontrar. Me interesaba conocer quiénes eran esas mujeres que habían encarado la tarea de conformar un espacio sobre género en un club de fútbol, cuáles eran sus trayectorias sociales, su relación con la militancia, con el feminismo y con el club. Quería observar sus vínculos con los dirigentes. Me preguntaba cómo serían recibidas por ellos. Así, en ese primer encuentro comencé a conocer de qué se trataba el área, y a partir de ese momento, empecé a participar junto con sus integrantes en reuniones, actividades, conversaciones y organización de eventos.

Luisina y Belén, dos jóvenes estudiantes de la carrera de Comunicación Social de la Universidad Nacional de La Plata, impulsaron la creación del espacio en el marco del trabajo final de la carrera. A Luisina, la idea le interesaba porque le apasiona el deporte y había militado en una agrupación feminista entre los ańos 2013 y 2016. Y a Belén, porque siempre fue fanática, «enferma del lobo», pero en los últimos ańos había comenzado a distanciarse de la cancha, un espacio que se había convertido para ella en un «reducto de producción y reproducción de lógicas machistas» del que ella se sentía cómplice si no hacía nada para cambiarlo. Por eso, su primera estrategia para no dejar de ir a la cancha había sido cambiar las letras de las canciones que cantaba allí: «donde dice puto, lo cambio por gil», o «huevos por ovarios", me comentó. Esta estrategia no es ingenua, si tenemos en cuenta que los cantos de cancha se han constituido históricamente como una forma concreta de ejercer poder, reafirmando el machismo estructural de la sociedad, como muestra Bundio (2016), pero que al mismo tiempo «en los cambios en los cantos de cancha es posible reconocer instancias de construcción de significados que exceden el marco futbolístico y se vinculan con procesos sociales más abarcativos» (2016, p. 273). Si las mujeres habían sido excluidas históricamente del ritual del aliento, el deseo y proyecto de transformar los cantos de cancha dentro de un folclore que no violente a las mujeres y las disidencias es una apuesta que, sin quedar exenta de dificultades, como pude observar en un partido de fútbol femenino en que las integrantes del área intentaban sin éxito cambiar las letras de los hits entonados por la hinchada, reviste un particular interés para las mujeres que habitan estos espacios.

Volviendo a la conformación del área, a Belén y Luisina se les ocurrió la idea de «hacer una secretaría de género en el Lobo». La concreción de esta idea, que originalmente aparecía como una fantasía demasiado ambiciosa, fue posible por 
los contactos que Belén había cosechado durante sus años de fanática. Ella sostiene que "conocía a algunas personas en el club, por ir, por estar». Movilizadas por el momento histórico que el movimiento feminista se encuentra atravesando en Argentina, decidieron avanzar con esa idea, articulando con los miembros de la Subcomisión de Cultura y Museo, nexo institucional que les permitió presentar el proyecto a la Comisión Directiva. De la mano de la agenda de género en el debate público, el proyecto fue rápidamente aprobado. Además, hubo una circunstancia que, desde el punto de vista de Luisina y Belén, fue clave a la hora de impulsar la generación del espacio: un conjunto de abusos sexuales a jugadores menores en el club Atlético Independiente que salieron a la luz a principios de 2018. Sensibilizados por «lo que había pasado en Independiente» y tras la preocupación de algunos padres de deportistas que se acercaron al club, los dirigentes de Gimnasia entendieron que era necesario comenzar a prestar atención a este tipo de cuestiones. En este sentido, creyeron que impulsar un área de género brindaría herramientas para evitar que cuestiones como esa sucedieran en el club. De aquí surgirá una de las mayores tensiones entre los dirigentes y el área que será analizada más adelante: en tanto ellos insistirían en la importancia de que ellas trabajen solo con las inferiores, la estrategia de las pibas apuntaba al machismo estructural del club.

Si recapitulamos hasta aquí, se puede mencionar que el surgimiento del área de género tiene que ver con un deseo de "hacer algo sobre género» en el club por dos estudiantes universitarias. En efecto, una de las características que compartirá la mayoría de las integrantes del área es el hecho de estar transitando carreras universitarias o de ser profesionales vinculadas con la comunicación y las ciencias humanas y sociales ${ }^{15}$.

La idea de "hacer algo» aparecerá recurrentemente en los discursos de las integrantes del área y en los vínculos que van estableciendo, y cuyos resultados han ido emergiendo a lo largo del trabajo de campo. Allí pude observar que "hacer algo» contenía desde la posibilidad de realizar una charla sobre fútbol femenino, hacer un manual para que cuando ellas no estén quede en el club, pensar actividades para trabajar sobre «estereotipos de género» con los y las deportistas o con las inferiores, realizar capacitaciones en perspectiva de género para entrenadores o el contacto con agrupaciones o espacios de género de otras instituciones. También implicó, por ejemplo, rastrear en los archivos del club la historia de deportistas mujeres destacadas, o realizar campañas de concientización contra la violencia de género. En efecto, esas fueron algunas de las múltiples actividades que realizaron desde que se formó el espacio.

15 Esta misma tendencia aparece en otros espacios de género con los que he tenido contacto a partir del proyecto UBACyT del cual soy parte, dirigido por Verónica Moreira: Deporte, cuerpo y género: etnografías sobre futbol, crossfit, running y boxeo en la Ciudad de Buenos Aires. Sería interesante seguir indagando en estas particularidades en torno a la composición social de las mujeres que participan de estos espacios. 
Además de Luisina y Belén, el área está compuesta por otras integrantes como Camila, que "es psicóloga y su hijo hace futsal en Gimnasia», y Johana, que es comunicadora social. También forma parte Sofía, una licenciada en ciencias políticas que se define «antes que feminista, tripera». En los últimos meses, el número de mujeres que se acercaron al espacio creció enormemente y actualmente son alrededor de treinta y trabajan por comisiones: algunas se ocupan de la parte de prensa, otras de dialogar con dirigentes y otras de articular con los espacios de otros clubes.

La heterogeneidad de trayectorias que se encuentran entre las integrantes del área es fundamental para comprender la especificidad del espacio. Si algunas de ellas buscan a partir del trabajo en el área "erradicar el machismo imperante en el club», otras encuentran allí un lugar donde canalizar sus ganas de hacer algo por Gimnasia, ganas que hasta el momento no encontraban dónde realizarse, en tanto entendían que los espacios de sociabilidad del club permanecían vedados para las mujeres. En este sentido, a Sofía — a quien siempre le interesó la política一, la participación en las asambleas del club se le representaba como hostil «porque era un lugar machista, por excelencia. Porque van todos hombres. Una vez fui, pero no, no... ¿Qué hacía ahí yo? Sola... Medio sapo de otro pozo». En este sentido, cuando se enteró de la creación del área decidió acercarse y así lo relata: «Yo quería deconstuirme, quería salir de los ámbitos donde yo había estado siempre. Muy cuidados, formales, católicos. Y quería empezar a involucrarme. Y era en Gimnasia. Y hacer algo por las mujeres. ¿Por qué no puedo encajar ahí? Yo lucho por ser libre. ¿Por qué no?».

Así, en el área se combinan trayectorias militantes, con apuestas subjetivas por pertenecer a un grupo, hacer algo por Gimnasia o luchar por los derechos de las mujeres. La importancia que reviste a su vez la sociabilidad informal ha sido puesta de manifiesto en las observaciones de campo, donde muchas de las «triperas» se acercan al área con la idea de encontrar un grupo de mujeres con el cual ir a la cancha, juntarse a fumar marihuana y tomar cerveza. En línea con la concepción de Bisso en torno a la política como entramada en las fronteras difusas entre lo «frívolo" y lo "comprometido", y tal como he analizado en trabajos anteriores (Hang, 2018), lo político se piensa integrado dentro de una serie de relaciones sociales y personales más amplia, y en las cuales las cuestiones personales son difícilmente escindibles, de manera tajante, de la actuación pública (Bisso, 2013). En efecto, tal heterogeneidad, con las contradicciones que sus integrantes reconocen y que seguiremos elaborando, es factible de pensarse en relación con el modo en que Natalucci y Rey (2018) caracterizan el movimiento de mujeres en Argentina en torno al \#NiUnaMenos, el cual «no implicó la conformación de una identidad feminista homogénea, sino más bien una de tipo heterogénea y polifónica, con una alta capacidad performativa en la agenda pública y en los repertorios de los sectores movilizados» (2018, p. 20). 
La mayoría de las integrantes del área de género de Gimnasia son jóvenes de sectores medios, estudiantes universitarias vinculadas con las ciencias sociales y militantes de agrupaciones políticas. Algunas han transitado por partidos de izquierda, otras en organizaciones más relacionadas con el peronismo/kirchnerismo, en particular en su rama estudiantil. Muchas de ellas coinciden en señalar un desencanto "por las estructuras patriarcales machistas de los partidos tradicionales». Son mujeres formadas en debates feministas.

Luisina y Belén sostienen que hay una experiencia en sus vidas que es la clave de su formación política: la de haber pasado por los Encuentros Nacionales de Mujeres $(\mathrm{ENM})^{16}$. Según ellas, esa experiencia las transformó. En su militancia en el club, hay un desafío de aprender a jugar un juego político con capitales adquiridos en otros lados, que valen en otros espacios, pero para hacerlos valer en el club tienen que articularlos con otros. Esta multiposicionalidad (Cefaï, 2011, p. 258) es crucial, y oscila entre la movilización de dos repertorios de acción. El repertorio del feminismo, basado en las nociones de horizontalidad e igualdad. La igualdad va en doble sentido: como ausencia de jerarquías, pero también como colectivo de mujeres que comparte una experiencia de subordinación y opresión, como muestra Masson (2007) a partir de los ENM y el del mundo de las instituciones deportivas que cuentan con fútbol profesional, estructurado en torno a la lógica del aguante que promueve una concepción de la rivalidad futbolística en términos de enemistad y que está atravesada por nociones como la valentía, el honor y la hombría vinculadas con los enfrentamientos físicos (Alabarces, Garriga Zucal y Moreira, 2008).

\section{LOS FEMINISMOS ENTRE CLUBES RIVALES. CONSTRUCCIÓN DE LA SORORIDAD Y CAPITALIZACIÓN DE LA RIVALIDAD}

Una referencia ineludible para pensar la especificidad del espacio de género en el CGE, remite a la clásica rivalidad con el club Estudiantes de La Plata. Como ha mostrado un conjunto de trabajos del campo de los estudios sociales del deporte, las identidades futbolísticas siempre se construyen alterizando con un otro. Garriga Zucal (2007) muestra a su vez la necesidad de que ese otro sea «local». La particularidad del caso argentino es que estas identidades se estructuraron sobre la retórica del aguante, categoría nativa que denota un sistema de honra y prestigio (Alabarces, Garriga Zucal y Moreira, 2008) relacionado indefectiblemente con la violencia y a los enfrentamientos físicos. La posesión del capital aguante por los hinchas configura un tipo de masculinidad hegemónica, basada en la tolerancia al dolor en los

\footnotetext{
16 Los Encuentros Nacionales de Mujeres tienen lugar todos los años, desde hace 34 años en distintos lugares del país. Se componen de talleres donde las mujeres abordan diversas temáticas, desde una perspectiva que resalta la horizontalidad y la igualdad.
} 
enfrentamientos físicos, en poner el cuerpo, poner huevos y ser macho. Desde esta óptica, ser hincha de un equipo va de la mano de tener aguante.

Habíamos visto que a Belén y Luisina estas ideas que en la cancha se materializaban en los cantos machistas, denigratorios hacia el rival, les comenzaban a hacer ruido. Sin embargo, cuestionar la dimensión machista de las canciones de cancha y la dimensión violenta de las rivalidades futbolísticas no implica para ellas cuestionar la rivalidad en sí. En efecto, sería imposible pensar a Gimnasia sin Estudiantes, porque «para definirme necesito distinguirme del otro», me comentó Belén. En la ciudad de La Plata, la rivalidad entre ambos equipos tiene un tinte particular que, como ha mostrado Godio (2009), con el correr de los años ha cristalizado en un imaginario según el cual Gimnasia aparece asociado con el mundo popular, mientras que Estudiantes aparece vinculado con los sectores más acomodados de la ciudad, a pesar de que el primero había nacido en 1887 como un club de la élite y el segundo en 1905, tras la prohibición de la práctica del fútbol en Gimnasia. Godio (2009) historiza esta rivalidad para concluir que: «La ciudad ha depositado entre ambos clubes, y dentro de los mismos, un escenario de disputa por coordenadas culturales más amplias, donde se juegan valores como colectividades, demandas sociales, estructuras emocionales, interpretación de acontecimientos valorados colectivamente, etc. Con este primer antecedente de origen se ha estructurado una ideal de estilos antagónicos entre ambos clubes» (p. 77 ).

Tal imaginario es el que activa Luisina cuando menciona que para ella "Gimnasia es pueblo», idea compartida por la totalidad de las integrantes del área.

En el caso que analizamos aquí, se puede pensar cómo esta rivalidad es reproducida con relación a las políticas en torno a las cuestiones de género que cada institución va llevando adelante. Unos días después de la primera reunión a la que asistí al área, leí en la prensa sobre el lanzamiento de la secretaría de género en Estudiantes. Al consultarle sobre este tema a Luisina, ella presentó algunos reparos acerca del modo en que el club rival entiende el género:

No sé si está muy piola lo que están haciendo. Porque hablan de fortalecer el liderazgo femenino como uno de los objetivos. Y yo no creo que el tema de género tenga que ver con una cuestión de liderazgo, que es una cuestión individual. El tema de género es una desigualdad estructural. Y creo que ahí le están errando. Y después también hicieron una publicación de que eran pioneros en la ciudad, por el hecho de tener alcanzapelotas mujeres... No sé si generás igualdad poniendo dos pibas de futbol femenino de alcanzapelotas.

Este tipo de acciones son comentadas en las reuniones del área y son relatadas de manera irónica y entre risas, resaltando lo marketinero de estas prácticas: «ese feminismo liberal de creer que sos pionero por poner mujeres alcanzapelotas o una mujer en la dirigencia». 
Ahora bien, más allá de estas críticas, reconocen la importancia de que en Estudiantes también estén «haciendo algo» y que es necesario acercarse a ellas para hacer algo juntas. Si bien Luisina asegura que las distancias con Estudiantes tienen que ver con las maneras de pensar y actuar las políticas de género, y que en un futuro la idea es trabajar en conjunto, otras integrantes como Sofía mencionarán la dificultad de establecer una relación de sororidad con Estudiantes, explicándolo en términos puramente sensibles y emotivos:

Porque me parece que estoy traicionando al club. Lo siento en mi interior. Como algo adentro que me dice: «no lo quiero hacer, no lo quiero hacer». La otra vez me saqué una foto que estaban ellas. $Y$ un amigo la ve, y me dice: «Yo no la hubiera sacado esa foto». Y yo quería llorar. Porque me había sacado con las de Estudiantes. Cosas así, que se me generan controversias adentro mío.

Las diferentes concepciones en torno al feminismo presentes en el espacio del área, y los vínculos que desde el área se establecen con otros clubes, y en particular con su clásico rival, pueden ser pensados en relación con aquello que Masson (2007) muestra en sus trabajos sobre el movimiento de mujeres, el cual se ha estructurado articulando una idea de igualdad sobre prácticas que incluyen el conflicto como dimensión constitutiva de la política feminista. Las rivalidades futbolísticas se tramitan para estas mujeres bajo la idea de sororidad, que implica compartir experiencias comunes de opresión y desigualdad. Construir esta sororidad en la rivalidad nada tiene de natural, y es en los pequeños detalles de sus acciones diarias donde se va produciendo la identidad de los feminismos en el fútbol: por ejemplo, nunca el flyer que invite a una actividad puede tener el color del equipo rival.

Dentro de las actividades que se llevaron adelante entre los clubes, una novedad ocurrió en el 34 ENM que tuvo lugar en la ciudad de La Plata en 2019, donde las mujeres de estos espacios confluyeron en dos talleres: Mujer e Instituciones Deportivas, y Mujer y Fútbol, en los que durante dos días hinchas, dirigentes y deportistas de todo el país compartieron sus experiencias en los clubes y pensaron estrategias de acción conjuntas y a futuro. Vale la pena mencionar aquí que, para el ENM, la gestión de las pibas del área logró que Gimnasia prestase sus instalaciones para alojar de manera gratuita a mujeres de todo el país que venían a la ciudad a participar del encuentro, para lo cual se organizaron desde unos meses antes con el fin de ocuparse de la seguridad, la difusión y las comidas de quienes se alojarían en el club. Para ello, realizaron "mateadas feministas ${ }^{17}$ en las que convocaban a todas las hinchas y socias a acercarse y colaborar y pensar lineamientos de acción.

17 El mate es una infusión típica argentina que tiene como característica ser tomado en grupo. Un mismo mate circula por todas las personas que lo comparten. La mateada refiere a un encuentro grupal, donde las personas se juntan a tomar mate, conversar, y compartir un momento sociable. 
Ahora bien, si para lograr conquistar la sororidad sin perder la rivalidad se requiere un sutil trabajo de articulación de las diferencias entre las hinchas y socias de distintos clubes, es esa misma rivalidad la que les permite, frente a otros actores como los dirigentes del club, conseguir cosas.

Una de las estrategias que las pibas ponen a jugar a la hora de obtener el permiso o aval por la dirigencia del club para realizar alguna actividad es mostrar lo que desde otros clubes (particularmente — pero no solo_ - Estudiantes) se ha realizado en cuestiones de género. La posibilidad de "ser pioneros en" (tener un área de género, poner mujeres alcanzapelotas, o que la voz del estadio sea mujer) es algo que ninguno de los dirigentes se quiere perder. «Le mostramos a la Comisión Directiva el flyer que sacaron ellos — por Estudiantes_ y nos preguntaron si podíamos hacer uno nosotras mejor y colgarlo en todas las redes», me comentó entre risas Belén. En definitiva, es posible pensar que, capitalizando las rivalidades futbolísticas, las mujeres del área logran hacer cosas: llamar la atención de los dirigentes y lograr su aval es fundamental para una estrategia política cuyo fin no es conseguir votos, sino ir ganando espacios y legitimidad para sensibilizar acerca de la desigualdad entre los géneros.

\section{Conquistas y Retrocesos: De Tifner a Maradona}

"Dos días los invito a militar en un club de fútbol. Dos días, a ver cuánto duran», me comentó Luisina, con la voz quebrada, luego de recibir algunas críticas de intelectuales y militantes feministas por «conciliar» y no repudiar públicamente la llegada de Maradona al club. Tomar la decisión de no realizar un comunicado público repudiando la llegada de Diego les había costado a las integrantes del área jornadas de debate, angustia y desacuerdos en las cuales comprendieron que cualquier proyecto político que las incluyera en el club implicaba no enfrentarse con el sentimiento popular de sus socios e hinchas. Entre posiciones que querían "prender fuego el carnet de socia» y realizar un escrache al club y otras que no podían disimular la alegría por la llegada del ídolo, la frase de Luisina grafica el encuentro de estos dos mundos. Las pibas comprendieron que, para sobrevivir políticamente en un club de fútbol, hay que conciliar. Si los dueños de la política en los clubes argentinos fueron siempre los profesionales liberales, los empresarios y los barras, las mujeres que buscan disputar poder allí ponen a jugar sus capitales políticos adquiridos en los espacios del feminismo, junto con sus credenciales académicas, para negociar con actores que manejan otros códigos.

Moreira (2010) ha mostrado la profunda interrelación entre el mundo del fútbol y la política, donde para los dirigentes varones, los capitales que les permiten disputar poder en los clubes tienen que ver con trayectorias al interior del 
club, acreditar vínculos de sangre con fundadores de la institución, pero también disponer de dinero para financiar campañas, contactos y tiempo libre. Para las mujeres, en cambio, se ha podido observar que son el aprendizaje político previo y las herramientas brindadas por las carreras universitarias las que les permiten, por ejemplo, hablar en público, exponer un problema o una demanda, o salir en un medio de comunicación. En este sentido, es interesante pensar el modo en tanto Belén como Luisina se apoyaron muchas veces en mi lectura "como socióloga" para que las ayude a pensar estrategias y posibilidades de acción.

Entra las conquistas que tuvieron desde el área, Luisina destaca como el «primer gran triunfo» haber incidido en la decisión de la Comisión Directiva de no convocar a un jugador con denuncias por «violencia de género». El 1 de febrero de 2019, se conoció la noticia de que el técnico de Gimnasia separaba a Hernán Tifner, un jugador que había protagonizado un video viral en el que se lo veía rayando el auto de su pareja, quien lo denunciaba por violencia de género. En este sentido, Luisina relata el rol del área de género en tal decisión como fundamental, en tanto fueron ellas quienes insistieron para que se aparte al jugador y se lo comunique a los socios desde una mirada que reponga que lo que se veía en el video era violencia de género. Así, sostiene que:

Para nosotras fue reimportante, porque se laburó de conjunto en casi todo el momento, hubo diálogo entre la comisión, prensa y marketing y nosotras. Es como que se terminó de consolidar nuestro espacio, donde si nosotras no hubiéramos estado, estoy segura que no se hubiera resuelto la situación como se resolvió. Así que fue como una primera gran gran victoria dentro del club, y dentro del fútbol en general; fuimos el primer club en hacer algo así.

Así, si bien no lograron que se rescinda el contrato del jugador, la decisión de que no sea convocado para jugar fue para ellas un gran triunfo, porque permitió instalar una preocupación entre los dirigentes y poner en discusión los sentidos sobre la violencia de género.

Medio año después tuvo lugar el primer partido de fútbol femenino en la era profesional, en el que Gimnasia enfrentó a Huracán en el estadio del bosque. Mientras esperábamos que comenzara el partido, las pibas del área colgaban, detrás del arco, una bandera que rezaba: «Aborto legal, seguro y gratuito». Ingresarla no había sido fácil. En Argentina las políticas de seguridad en los estadios prohíben el ingreso de banderas con consignas políticas, y el reclamo por el aborto legal es uno de ellos. Las pibas creían que, por ser parte del área, podían llegar a ser revisadas con más detalle que sus pares masculinos. Optaron por pedir a algunos compañeros de una de las filiales del Lobo que ingresara la bandera. El partido tuvo lugar a pocos días de la llegada de Maradona al club, por lo que el «tema Maradona» marcaba el ritmo de las conversaciones. Jeny me contaba entre risas que había estado a punto de 
separarse de su pareja, quien estaba extasiado de felicidad con la llegada de Diego al club. Ella quería convencerlo sobre los motivos por los cuales, para las mujeres feministas del Lobo, la llegada del ídolo no significaba una buena noticia sino un retroceso en las políticas de género que desde el área venían llevando adelante. Su esfuerzo, como el de las otras integrantes del área, fue en vano, ya que para la gran mayoría del pueblo tripero la llegada de Diego provocó una alegría inconmensurable. "Y yo con la felicidad del pueblo no me meto», comentó Jeny resignada, en una frase que condensa la complejidad de la tarea que los feminismos en los clubes vienen llevando adelante.

Llegar a tal consenso no fue un proceso sin costos para las pibas del área. Después de un año y medio de trabajo intenso, durante el cual lograron referenciarse tanto hacia el interior del club como hacia afuera, por ejemplo, siendo consultadas por muchísimas mujeres de distintos clubes del país que buscaban asesoramiento para crear espacios similares, aceptar la llegada de Maradona implicó al interior del espacio la emergencia de conflictos que venían siendo tramitados y resueltos bajo las ideas de igualdad, horizontalidad y sororidad. Sin embargo, las discusiones comenzaron a versar entre si era mejor mantener una política horizontal o establecer jerarquías con el fin de negociar con interlocutores con poder; si era más deseable transformar el club desde adentro, o ir corriéndose más hacia el exterior y desde ahí tensionar sin tener que rendir cuentas a nadie. A su vez, se iban evidenciando tensiones entre aquellas que se reconocían como "más feministas» y aquellas que se identificaban "primero triperas». Y si habían logrado definirse como un espacio político, pero no partidario, algunas decisiones como por ejemplo en relación con qué columna marchar en el Encuentro Nacional de Mujeres, aparecieron como problemáticas para algunas de ellas ${ }^{18}$.

Se habían ido configurando así dos grandes posturas que con el correr del tiempo, y la intensidad que implicó para las pibas la llegada de Maradona, y luego la organización del Encuentro Nacional de Mujeres (ENM), llevó hacia finales del 2019 al alejamiento de Luisina, Sofía y otras mujeres, quienes, sin embargo, pasaron a ocupar otros espacios adentro del club. Luisina avanzó con un proyecto para crear un Observatorio sobre mujeres y disidencias en el club, desde donde rastrear la historia de las mujeres y disidencias socias, deportistas y trabajadoras

18 Los ENM finalizan con una marcha que recorre la ciudad en la que se organiza. La marcha que cerr el 34 ENM en la ciudad de La Plata fue la más masiva de la historia de los encuentros, en la que se estima que participaron más de 300000 mujeres. Por primera vez contó con una columna encabezada por la Coordinadora de Fútbol Feminista, en la que confluyeron mujeres y disidencias vinculadas con el fútbol. Sin embargo, en un año de elecciones nacionales y a pocos días de aquellas, las mujeres del área de Gimnasia decidieron marchar en la columna del Frente de Todxs, el frente electoral que promovió la candidatura a presidente de la nación de Alberto Fernández. 
del Lobo. Las otras chicas se fueron acercando a diversos espacios institucionales, como la secretaría de Cultura y Museo y la subcomisión de fútbol femenino.

Para cerrar este apartado, es preciso promover una mirada reflexiva sobre el trabajo que llevé adelante este tiempo y la relación que establecí con mis interlocutoras, con quienes construí una relación de confianza y afecto, además de que ellas me hicieron parte de su red de relaciones y contactos estratégicos con quienes articulaban para sus actividades ${ }^{19}$. Rastrear la política en el club desde una perspectiva etnográfica (Ferraudi Curto, 2010; Hang, 2018), implica estar atenta al modo en que la política se hacía también conmigo adentro. Cada vez que ellas pedían mi opinión sobre algún tema, yo insistía en la importancia de que siguieran juntas, ocupando ese espacio que históricamente había sido negado a las mujeres y que tanto había costado conseguir. El diálogo con mis interlocutoras fue constante, y ellas encontraron en mis opiniones y lecturas herramientas para pensar su actividad política.

La antropóloga Verena Stolcke (1996) sostiene que la antropología feminista desde el principio entendió la investigación como una herramienta esencial para la emancipación social. En este sentido, mi inmersión en el campo iba de la mano de la simpatía que me generaba el trabajo que ellas realizaban para erradicar el machismo. Por eso mi tristeza fue enorme cuando Luisina me comentó que se alejaba del espacio. Luisina y Belén me insistían en que estaba bien, que no importaba, que ellas iban a seguir trabajando para el club. Me parece importante entonces volver al modo en que Masson (2007) caracteriza al feminismo argentino como un movimiento necesariamente atravesado por el conflicto como una forma de relación, una figuración particular y no como un problema no resuelto dentro de la militancia feminista. Despersonalizar el conflicto, dice la autora, es, a su vez, una de las estrategias que permite a las feministas manejar al nivel de una lógica política conflictos hasta entonces considerados singulares. Insistir, como lo hacía Luisina en que el problema fueron diferencias políticas, distintas maneras de entender la acción política en el club, era devolver la dimensión política a su alejamiento, permitiendo a su vez la posibilidad de seguir articulando entre ellas, ahora desde diferentes espacios y con el conflicto como elemento constitutivo de su dinámica política.

\section{Consideraciones Finales}

El acercamiento del feminismo al mundo del fútbol ocurre de manera masiva en Argentina a partir del \#NiUnaMenos, impulsando la creación de espacios de género

19 En este sentido, tras reflexionar largamente acerca de las expectativas que ellas generaron para conmigo, entendí que les resultaba muy interesante mi lugar como socióloga, vinculada con la academia, en un contexto de gran crecimiento de los estudios sobre género y deporte (Álvarez Litke, 2018; Hijós, 2018). 
en una multiplicidad de clubes del país que apuntan a promover políticas desde una perspectiva de género que visibilice y rompa la desigualdad y la subordinación de las mujeres, y que permita repensar las masculinidades, los estereotipos de género y establecer maneras de relacionarse antipatriarcales que promuevan un fútbol por fuera de la misoginia y el machismo que históricamente caracterizaran al fútbol argentino.

Este artículo procuró dar cuenta de las formas específicas a partir de las cuales un colectivo de mujeres feministas se organiza políticamente en el club Gimnasia y Esgrima de La Plata y disputa poder con el objetivo de erradicar el machismo del club, combinando dos lógicas políticas: las del mundo del fútbol y las del feminismo. Esta combinación supone un trabajo de negociación y articulación constante tanto al interior del espacio entre posiciones heterogéneas como con los dirigentes y socios del club. Lograr un equilibrio entre estas dos lógicas no es una tarea sencilla para las pibas, quienes aprenden a movilizar los distintos repertorios de acción a partir de las situaciones problemáticas en torno a las cuales el colectivo se va definiendo. La llegada de Maradona al club fue una de las situaciones claves en torno a las cuales se pusieron en juego definiciones y estrategias políticas, que las impulsó a repensar su capacidad de acción, sus interlocutores, sus redes y su agenda futura. Promovió un proceso de reacomodamiento de las protagonistas, donde algunas quedaron adentro del espacio y otras afuera, activando nuevas áreas desde los cuales trabajar la perspectiva de género, el objetivo central de las mujeres feministas que militan en el club.

El caso del área de género de Gimnasia, permite iluminar algunas características de un movimiento social más amplio que refiere al movimiento de mujeres argentino a partir del \#NiUnaMenos. Una heterogeneidad de mujeres, con trayectorias diversas y con apuestas políticas diferentes, que confluyen en un lugar tradicionalmente masculino, y que se proponen entre sus objetivos erradicar el machismo estructural aprovechando el contexto político de avance de conquista de derechos de las mujeres. Pero también, mujeres que se acercan al espacio para acompañarse, para encontrar un grupo con el cual ir a la cancha, hacer algo por Gimnasia o por las mujeres.

En definitiva, se ha analizado cómo las mujeres que conforman el área de género del club Gimnasia han ido construyendo una identificación en torno a la categoría de «feministas triperas», que lejos de presentarse como una identidad homogénea y sin conflicto, fluctúa entre quienes se definen como «antes que feministas, triperas», o "más feministas que triperas». Este proceso de identificación supone a la vez una alterización con unos «otros» que van construyendo en ese camino: a veces los feminismos de otros clubes, a veces los dirigentes de Gimnasia. En este intercambio, van estableciendo alianzas y negociaciones.

Finalmente, y a partir del análisis de los vínculos que desde el área se establecen con otros clubes, es posible comenzar a iluminar la pregunta por el modo en que una 
conciencia de mujeres se articula en el marco de un club de fútbol, pero también entre los distintos clubes, articulación que para el fútbol argentino es una novedad. Seguir indagando en esta línea nos permitirá profundizar en los modos específicos en que la acción colectiva se compone con el conflicto y la diferencia como elementos centrales que se tramitan, en este caso, bajo los conceptos de sororidad e igualdad.

\section{REFERENCIAS}

Alabarces, P. (2013) Fútbol, leonas, rugbiers y patria. El nacionalismo deportivo y las mercancías. Nueva Sociedad, 248, 28-42.

Alabarces, P., Garriga Zucal, J. y Moreira, V. (2008). El «aguante» y las hinchadas argentinas: una relación violenta. Horizontes Antropológicos, 14(30). 113-136.

Álvarez Litke, M. (2018). Marcando la cancha: una aproximación al fútbol femenino desde las ciencias sociales. Cuestiones de Sociología, (18), e055. https://doi. org/10.24215/23468904e055

Anderson, P. (2017.) Re-conceiving the Patriotic Mission of Women: Sports and Civic Activism in Argentina, 1900-1946. En Deportismo! Female Sports and Gender Change in Argentina: 1900-1946 [tesis PhD in History inédita (ABD status)]. University of Toronto, Canadá.

Bisso, A. (2013). El lugar de la sociabilidad como factor de análisis en los estudios de historiografía política de la democracia renovada. Cuestiones de Sociología, 9. FaHCE, UNLP.

Bundio, J. (2016). Un análisis del contenido y la melodía de los cantos de cancha desde sus orígenes hasta las tendencias actuales. En A. Levoratti y V. Moreira (comps.), Deporte, cultura y sociedad. Estudios socio-antropológicos en Argentina (pp. 271-294). Buenos Aires: Teseo.

Burgo, A. (2016). El partido. Argentina-Inglaterra 1986. Buenos Aires: Tusquets.

Caminotti, M. (2017). La paridad politica en Argentina: avances y desafios. Buenos Aires: Programa Naciones Unidas para el Desarrollo - PNUD; Lima: IDEA Internacional; Panamá: Organización de las Naciones Unidas. Mujeres. Recuperado de https:// observatoriogenero.senado-ba.gov.ar/Informes/PNUDArgent-InfAteneaArgentina. pdf

Cefaï, D. (2011). Diez propuestas para el estudio de las movilizaciones colectivas. De la experiencia al compromiso. Revista de Sociología, 26, 137-166.

Conde, M. y Rodríguez, M. G. (2002) Mujeres en el fútbol argentino: sobre prácticas y representaciones. Alteridades, 12(23), 93-106.

Daskal, R. y Moreira, V. (2017). Clubes argentinos: debates sobre un modelo. San Martín: UNSAM Edita.

De Marziani, E. y Pierini, M. (2019). Participación activa de mujeres en institución sociodeportiva: Ejecución de la Subcomisión de Género del Club de Gimnasia y Esgrima La Plata [tesis de grado]. Facultad de Periodismo y Comunicación Social - UNLP. 
Elsey, B. (2019). Energizadas pelo movimento de mulheres «\#NiUnaMenos», as equipes de futebol feminino desafiam os patriarcas do esporte-rei da América Latina. FuLiA / UFMG, 4(1), 39-50. https://doi.org/10.17851/2526-4494.4.1.39-50

Ferraudi Curto, M. C. (2010). Etnografía de la política en el proceso de urbanización de una villa del Gran Buenos Aires [tesis de doctorado en Ciencias Sociales]. Universidad Nacional de General Sarmiento; Instituto de Desarrollo Económico y Social.

Frydenberg, J. (2002). Los clubes deportivos con fútbol profesional argentinos y el tipo o formato social bajo el cual se organizan: asociaciones civiles o sociedades anónimas. Aportes para un debate acerca de realidades y modelos ideales, pasiones e intereses. Recuperado de www.efdeportes.com/ Revista Digital, 51, agosto. Buenos Aires.

Frydenberg, J. y Daskal, R. (2010) Fútbol, historia y politica. Buenos Aires: Aurelia Libros. Estudio social. Rivera.

Garriga Zucal, J. (2007) Entre identidades nacionales y locales. Los simpatizantes de un club de fútbol argentino ante los avatares de su selección nacional. Papeles del CEIC, (2), septiembre.

Godio, M. (2009). «Con una mano lo acaricias y con la otra lo abofeteas»-El club de fútbol ysus dirigentes en el imaginario de las profesiones: un campo de fuerzas en las formas experimentales del poder y la política en Argentina. Vibrant - Virtual Brazilian Anthropology, 6(2). July to December 2009. Brasília, ABA. Recuperado de http://www.vibrant.org. br/issues/v6n2/matias-godio-con-una-mano-lo-acaricias-y-con-la-otra-lo-abofeteas/

Hall, S. (1984). Notas sobre la desconstrucción de «lo popular». En R. Samuel (ed.), Historia popular y teoría socialista. Barcelona: Crítica.

Hang, J. (2018). Política y sociabilidad en un club social y deportivo de la ciudad de La Plata [tesis de doctorado en Ciencias Sociales]. Universidad Nacional de La Plata, Facultad de Humanidades y Ciencias de la Educación. Recuperado de http://www. memoria.fahce.unlp.edu.ar/tesis/te.1599/te.1599.pdf

Hijós, N. (2018). Apuntes bibliográficos para acercarnos a la pregunta por el género en el deporte. CuestionesdeSociología, (18), e059.https://doi.org/10.24215/23468904e059

Masson, L. (2007). Feministas en todas partes. Una etnografia de espacios y narrativas feministas en Argentina. Buenos Aires: Sudamericana.

Moreira, V. (2010). La política futbolizada: los dirigentes deportivos y las redes políticoterritoriales en Avellaneda [tesis de doctorado en Ciencias Sociales]. Universidad de Buenos Aires, Facultad de Ciencias Sociales, Buenos Aires.

Moreira, V. (2018). Fútbol, modelos jurídicos y mercado: el dilema de los clubes en Sudamérica. Revista Critica de Ciências Sociais, 116, 135-154. https://doi.org/10.4000/ rccs. 7327

Natalucci, A. y Rey, J. (2018). ¿Una nueva oleada feminista? Agendas de género, repertorios de acción y colectivos de mujeres (Argentina, 2015-2018). Revista de Estudios Politicos y Estratégicos, 6(2), 14-34.

Pujol, A. (2019). ¡Qué jugadora! Un siglo de fútbol femenino en Argentina. Buenos Aires: Ariel. 
Scharagrodsky, P. A. (2014). Las feministas y su «mirada» sobre la Educación Física «femenina». Argentina, primeras décadas del siglo XX. En E. Camblor, O. Ron, N. Hernández y otros (coords.), Prácticas de la educación fisica. La Plata: Universidad Nacional de La Plata, Facultad de Humanidades y Ciencias de la Educación. (Colectiva y Monográfica; 2). En Memoria Académica. Recuperado de http://www. memoria.fahce.unlp.edu.ar/libros/pm.393/pm.393.pdf

Stolke, V. (1996) Antropología del género. El cómo y el porqué de las mujeres. En J. Prat y A. Martínez (eds.), Ensayos de Antropología Cultural. Homenaje a Claudio EstevaFabregat (pp. 335-344). Barcelona: Ariel. 